Araştırma Makalesi - Research Article

\title{
Çevre Sıcaklığının Dolaşımlı Akışkan Yataklı Kazanın Ekserji Performansı Üzerindeki Etkisi
}

\author{
Mesut YAZICI ${ }^{1 *}$, Ramazan KÖSE ${ }^{2}$ \\ Geliş / Received: 06/10/2019 \\ Revize / Revised: 19/11/2019 \\ Kabul / Accepted: 09/12/2019 \\ ÖZ \\ Sunulan bu çalışmada, Eskişehir'in Seyitgazi ilçesinde yer alan bir endüstriyel tesisteki $75 \mathrm{t} / \mathrm{h}$ buhar kapasiteli \\ dolaşımlı akışkan yataklı kazanın konvansiyonel ekserji analizi yapılmıştır. Yapılan analizde; çevre \\ sıcaklığındaki değişimin, kazan ve hava isıtıcısının ekserji performansına olan etkisi irdelenmiştir. Bunun için \\ standart ölü hal koşulu $25^{\circ} \mathrm{C}, 101,325 \mathrm{kPa}$ ve ölçüm değerlerinin ortalaması olarak $17,27^{\circ} \mathrm{C}, 89,4 \mathrm{kPa}$ 'nn yanı sıra \\ $30^{\circ} \mathrm{C}, 28^{\circ} \mathrm{C}, 20^{\circ} \mathrm{C}, 15^{\circ} \mathrm{C}$ ve $12^{\circ} \mathrm{C}$ için hesaplamalar yapılmıştır. Dolaşımlı akışkan yataklı kazan bölümler halinde \\ incelenmesinden ziyade bir bütün olarak kabul edilmiştir. Hava 1 sıtıcısı ise kazandan ayrı olarak \\ değerlendirilmiştir. Yapılan hesaplamalar sonucunda kazan ve hava 1sıtıcısında gerçekleşen ekserji kayıpları \\ belirlenmiştir. Ayrıca kazan ve hava isıtıcısının ekserji verimleri hesaplanarak ekserji performansı ortaya \\ çıkarılmıştır. Bu çalışma, dolaşımlı akışkan yataklı kazanın ve hava ısıtıcının ekserji performans kriterlerinin \\ çevre sıcaklığındaki değişimden önemli ölçüde etkilendiğini göstermiştir.
}

Anahtar Kelimeler- Akışkan Yataklı Kazanlar, Ekserji Analizi, Ekserji Yıkımı, Ekserji Performansı

1*Sorumlu yazar iletişim: mesut.yazici@dpu.edu.tr (https://orcid.org/0000-0001-6379-8396)

Enerji Sistemleri Mühendisliği, Kütahya Dumlupınar Üniversitesi, Simav Teknoloji Fakültesi Muradınlar Kampüsü, Simav 2illetişim: ramazan.kose@dpu.edu.tr (https://orcid.org/0000-0001-6041-6591)

Makine Mühendisliği, Kütahya Dumlupınar Üniversitesi, Evliya Çelebi Yerleşkesi Tavşanlı Yolu 10.km KÜTAHYA 


\title{
Effect Ambient Temperature on Exergy Performance of Circulating Fluidized Bed Boiler
}

\begin{abstract}
In this study, conventional exergy analysis of circulating fluidized bed boiler with $75 \mathrm{t} / \mathrm{h}$ steam capacity in an industrial facility located in Seyitgazi district of Eskişehir, Turkey was carried out. In this analysis, it was aimed to see the effect of the change in ambient temperature on the exergy performance of the boiler and air heater. For this purpose, exergy values for the standard dead state $25^{\circ} \mathrm{C} 101.325 \mathrm{kPa}$ and the average measurement values of $17.27^{\circ} \mathrm{C} 89.4 \mathrm{kPa}$ as well as $30^{\circ} \mathrm{C}, 28^{\circ} \mathrm{C}, 20^{\circ} \mathrm{C}, 15^{\circ} \mathrm{C}$ and $12^{\circ} \mathrm{C}$ were calculated. The circulating fluidized bed boiler is considered to be a whole rather than being examined in sections. The air heater was evaluated separately from the boiler. As a result of the calculations, exergy losses realized in boiler and air heater were determined. In addition, exergy performances of boiler and air heater was determined by calculating exergy efficiency. This study showed that exergy performance criteria of circulating fluidized bed boiler and air heater were significantly affected by the change in ambient temperature.
\end{abstract}




\section{GIRIŞ}

Enerji üretim proseslerinin ve enerji tüketen makinaların verimliliği sürdürülebilir enerji politikaları için önemli bir faktördür. Performans tespit çalışmalarında genellikle maliyetlerin düşürülmesi, kullanım ömrünün artması ve çevreye olan olumsuz etkilerin azaltılması için verimlilik seviyesi araştırılmaktadır. Bu çerçevede en çok tercih edilen yöntem enerji analizidir. Ancak bu yöntem karmaşık sistemlerde yetersiz kalmaktadır. Bu noktada ekserji analizi daha derinlemesine analiz yapma imkânı tanımaktadır. Ekserji analizi tasarım, optimizasyon ve gelişim aşamaları için etkili bir araçtır [1,2]. Geçmişte yapılan birçok bilimsel çalışmada kullanılan ekserji analizinin; bir sistemde gerçekleşen tersinmezliklerin yerini, şiddetini ve sebebini doğru bir şekilde tespit etmesiyle güvenilirliği ispat edilmiştir [3].

Akışkan yataklı kazanlar ve pülverize kömür yakma sistemlerinin bulunduğu güç santrallerinin performanslarının ölçülmesinde ekserji analizi en çok başvurulan yöntemlerden biridir [4-9]. Erdem vd. [10] Türkiye'deki 9 adet termik santralin performansını karşılaştırmalı olarak, Koreneos vd. [11] 300 MW'lık linyit yakan termik santralin, Pattanyak ve Sahu [12] 460 MW'lık işletme yükündeki pülverize kömür yakan termik santralin, Bolatturk vd. [13] Ankara-Çayırhan termik santralinin, Ahmadi ve Toghraie [14] 200 MW'lık termik santralin, Si vd. [15] 1000 MW çift tekrar kızdırmalı ultra süper kritik güç santralinin performanslarını ekserji analizi uygulayarak ölçmüştürler. Yapılan bu çalışmalar en büyük ekserji yıkımının kazanlarda gerçekleştiğini ortaya çıkarmıştır.

Ekserji analizi uygulanma amacı açısından karar verme mekanizması olarak da kullanılmaktadır. Bu çerçevede, birçok çalışmada sistem performansının olumlu etkilendiği rapor edilmiştir [16-20]. Xiong vd. [21], oksi-yanma prosesinin termodinamik özelliklerini tespit etmek için $600 \mathrm{MW}$ 'llk pülverize kömür yakan termik santraline ekserji analizi uygulamıştırlar. Bu çalışmada konvansiyonel yanma ve oksi-yanma prosesinin ekserji yıkım ve verimliliği değerleri karşılaştırılmıştır. Han vd. [22], linyitin baca gazı ön kurutma işleminin enerji tasarrufu potansiyelini araştırmıştırlar. Burada konvansiyonel ve ön kurutmalı yakma prosesinin enerji ve ekserji verimlilikleri karşılaştırılmıştır. Ekserji analizi incelenen sistem üzerinde yapılan değişikliklerin etkisini görmede avantaj sağlamaktadır. Elhelw vd. [23], kondenser basıncını ve IPT (Orta Basınç Türbini) giriş basıncındaki düşüşün, IPT ve HPT (Yüksek Basınç Türbini) girişindeki buhar sıcaklığındaki artışın sistem performansındaki etkisini ekserji analizi uygulayarak incelemiştirler.

Bir sistemin ekserjisi enerjinin aksine tersinmezliklerden dolay1 korunmamaktadır [24-29]. Sistemde gerçekleşen tersinmezliklerden dolayı ekserji yıkımları gerçekleşmektedir. İncelenen bir sistemin potansiyelinin geliştirilmesi için ekserji yıkım miktarı ve yerinin tespit edilmesi büyük kolaylık sağlamaktadır. Bu sebeple son yıllarda birçok yakma sistemi içeren tesisler ekserji yıkımı tespiti için bilimsel çalışmalara vaka olmuştur [3032]. Wang vd. [33], 600 MW'lık süper kritik kömür yakan termik santralin ekserji yıkımı ve kirletici emisyon özelliklerini araştırmıştırlar. Ekserji analizi ile bir sistemin bütünü değerlendirilebildiği gibi sistemde bulunan her bir alt bölüm ayrı ayrı analiz edilebilmektedir. Böylece sistem içerisindeki verimsiz noktalar kolaylıkla tespit edilebilmektedir. Hepbaslı [34], petrol şeyli yakan dolaşımlı akışkan yataklı kazanlar için ekserjitik model oluşturmuştur ve bunu işletme halindeki $65 \mathrm{t} / \mathrm{h}$ buhar kapasiteli petrol şeyli yakan dolaşımlı akışkan yataklı kazana uygulamıştır. Çallak vd. [35], İzmir'de bir tekstil tesisinde yer alan akışkan yataklı kazan ve 1Sı geri kazanım buhar üreticinin gerçek verileri üzerinden ilk önce konvansiyonel ekserji sonra da ileri ekserji analizini gerçekleştirmişlerdir. Behbahanina vd. [36], bir buhar kazanının performansını değerlendirmek için ASME ptc.4.1 prensibine dayanan ekserji tespit metodunu önermişlerdir. Zhang vd. [37], kömürle çalışan endüstriyel kazanların çalışmasını iyileştirmek için bir ekserji analiz modeli oluşturmuşlar. Sharma ve Singh [38], bir kombine çevrim termik santralindeki kazanın kızdırıcı, evaparator ve ekonomizerini farklı ölü hal koşullarındaki ekserji kayıp ve verimlerini araştırmıştırlar.

Ekserji terimi sistem ve etkileşimde olduğu çevre koşullarıyla ilgili bir kavramdır. Bu noktadan hareketle sıcaklık, basınç gibi çevresel koşullardaki değişimin ekserji verimi üzerindeki etkisi araştırılan bir diğer konudur. Kopac ve Hilalci [39] ortam sıcaklığının, bir termik santralin bileşenlerinin verimlilik hataları ve rasyonel verimliliği üzerine etkisini araştırmak için ekserji analizi uygulamışlardır. Regulagadda vd. [40], 32 MW kapasiteli kömür yakan termik santralinin farklı sıcaklık, basınç ve akış oranlarındaki çalışma koşulları için kazan ve türbinin enerji ve ekserji analizi çalışmasını yürütmüşlerdir. Eskin vd. [41], 7,7 MW kapasiteli bir akışkan yataklı yakma sistemine sahip termik santraline termodinamiğin birinci ve ikinci yasa analizini 
uygulamışlardır. Ayrıca ortam sıcaklığının ve fazla hava miktarının ikinci yasa verimi üzerindeki etkisini incelemişlerdir. Ozdil vd. [42], Adana'da bulunan 6,5 MW'lık kuvvet santrali için ortam sıcaklığındaki değişimin birinci ve ikinci yasa verimliliklerini incelemiştirler. Buna göre ortam sıcaklığı arttıkça akışkan yataklı kazanın ikinci yasa veriminde artış gözlemlemişlerdir. Arslan [43], Seyitömer termik santralinde meydana gelen enerji kayıpları ve yerlerinin tespit edilerek verimliliğin artırılması için enerji ve ekserji analizi uygulamıştır. Bu çalışmaların yanı sıra Aljundi [44] 396 MW'lık termik santralin tüm alt sistemlerinin farklı çevre sıcaklıklarındaki ekserji verimi ve ekserji yıkımı değişimini araştırmıştır.

Sunulan bu çalışmada, ölü hal koşullarındaki değişimin 75 t/h buhar kapasiteli akışkan yataklı kazan ve hava ısıtıcısının ekserji verimlerine etkisi incelenmiştir. Ayrıca ekserji yıkımı, nispi ekserji yıkımı, yakıt tüketim oranı, üretkenlik eksikliği oranı ve ekserjetik gelişme potansiyeli miktarı gibi ekserji performans parametreleri araştırılmıştır. Çalışmada kazan alt bölümlere ayrılmamış ve bir bütün olarak kabul edilmiştir. Kazan ve hava 1sıtıcısına ait gerçek veriler ölçümler yapılarak elde edilmiştir. Elde edilen veriler oluşturulan termodinamik modelde uygulanarak kazan ve hava isıtıcısının ekserji analizleri yapılmıştır.

\section{DOLAŞIMLI AKIŞKAN YATAKLI KAZANIN GENEL ÖZELLİKLERİ}

Dolaşımlı akışkan yataklı buhar kazanı, $4500 \mathrm{kPa} / 455^{\circ} \mathrm{C}$ kızdırıcı çıkış basınç ve sıcaklık şartlarında buhar üreten, doğal dolaşımlı buhar kazanıdır [45]. Kazanın orta kısmı refrakter kaplamalı siklon ayırıcıdan oluşmaktadır. Siklon sonrası ikinci geçişte 1sı transfer yüzeyleri yerleştirilmiştir. Baca gazı, ikinci geçiş sonrasında hava isıtıcılarından ve ESP'den geçer ve daha sonra bacadan atmosfere salınmaktadır. Dolaşımlı akışkan yataklı kazana ait tasarım değerleri Tablo 1'de verilmiştir [45]. Buna göre $130^{\circ} \mathrm{C}$ sıcaklıkta kazana giren besleme suyu $455^{\circ} \mathrm{C}$ sicaklık, 45 bar basınçta saatte 75 ton debiye sahip buhara dönüşmektedir. Yatak sıcaklı̆̆ 1 $850^{\circ} \mathrm{C}$ 'yi bulurken kazandan çıkan baca gazının sıcaklığı $130^{\circ} \mathrm{C}$ 'dir [45].

Tablo 1. Kazanın tasarım parametreleri

\begin{tabular}{|c|c|c|}
\hline Ana Parametreler & Birim & Değer \\
\hline Kazan Nominal Gücü & MWt & 59,91 \\
\hline Buhar Çıkıș Debisi & $\mathrm{t} / \mathrm{h}$ & 75 \\
\hline Buhar Basinc1 & $\mathrm{kPa}$ & 4500 \\
\hline Buhar Sicaklı̆̆g & ${ }^{\circ} \mathrm{C}$ & 455 \\
\hline Besleme Suyu Sicaklığ & ${ }^{\circ} \mathrm{C}$ & 130 \\
\hline Yatak Sicaklığı & ${ }^{\circ} \mathrm{C}$ & 850 \\
\hline Fan Çıkışı Hava Sıcaklığı & ${ }^{\circ} \mathrm{C}$ & 35 \\
\hline Hava Isıtıcı Sonrası Sicaklık & ${ }^{\circ} \mathrm{C}$ & 200 \\
\hline Hava Fazlalık Katsayısı & - & 1,2 \\
\hline Bacagazı Sicaklığı & ${ }^{\circ} \mathrm{C}$ & 130 \\
\hline Kazanın Verimliliği & $\%$ & 91 \\
\hline Yük Değişim Meğili & $\% /$ dak & 4 \\
\hline Kömür Tüketimi & $\mathrm{kg} / \mathrm{s}$ & 3,54 \\
\hline Kireçtaşı Tüketimi & $\mathrm{kg} / \mathrm{s}$ & 0,25 \\
\hline
\end{tabular}

\section{GERÇEK VERILLERIN ELDE EDİLMESİ}

$\mathrm{Bu}$ çalışmada hesaplamalar gerçek veriler üzerinden yapılmıştır. Bunun için öncelikle performans değerlendirmesi için ölçüm alınacak noktalar tespit edilmiştir ve Şekil 1 de verilmiştir. Kazanın bütünü ve hava 1sıtıcısı birbirlerinden ayrı kontrol hacimleri olarak kabul edilmiştir. Buna uygun olarak, kazana enerji girdisi sağlayacak olan yakıt (1), yanmaya katılan birincil (2) ve ikincil (3) yanma havası, ekonomizere giren besleme suyu (4) sisteme girenler olarak değerlendirmeye alınmıştır. Bunun yanı sıra kazandan çıkan baca gazı (6), kızdırıcıdan çıkan ana buhar (5) ise sistemden çıkanlar olarak belirlenmiştir. Hava 1sıtıcısında ise ön 1sıtmaya uğradıktan sonra hava ısitıcısına gelen birincil (7) ve ikincil (8) yanma havası ve kazandan sonra hava isitıcısına giren baca gazı (6) sisteme girenler olarak değerlendirilmiştir. Sistemden çıkanlar ise 1sıtılarak kazana gönderilen birincil (2) ve ikincil (3) yanma havası ve hava 1sıtıcısından ESP'ye (Elektrostatik Filtre) gönderilen baca gazıdır (9). Performans test prosedürü ASME PTC-40 uyarınca gerçekleştirilmiştir [45]. Kazan 72 saatlik kararlı çalışma rejimini takiben, 4 saat boyunca tam yükte çalıştırılmıştır. Belirtilen zaman dilimi sürecinde performans testi için gerekli ölçümler gerçekleştirilmiştir. Besleme suyu giriş ve ana buhar çıkış debi, basınç ve sıcaklığı, birincil ve 
ikincil yanma havasının kazana girişinde, hava 1sıtıcı giriş ve çıkışındaki debi, basınç ve sıcaklık değerleri ölçülmüştür. Bu ölçümlerde debi ölçümü için Honeywell marka vortex 100 tipi dijital akış metre, basınç ölçümü için Autrol marka APT3200-G6M11E1191-M1 tipi ve APLISE marka APC-2000ALW tipi basınç ölçerler, sıcaklık ölçümü için ise Emko MARKA 1000/1EC/PT100 CLASS A tipi dijital sıcaklık ölçer kullanılmıştır. Ayrıca Testo 480 ölçüm cihazı ile hava emiş noktalarındaki ortam basıncı, sıcaklığı ve nemi ölçülmüştür. Test süresince kurum üfleme ve blöfler kapalı tutulmuş ve kazan işletme koşulları test esaslarını bozmayacak değerler arasında kalması sağlanmıştır. Kömür, kireçtaşı, cüruf ve külden analizler için ilgili standarda uygun olarak numuneler alınmıştır. Testo 350XL gaz analiz cihazı ile baca gazı emisyon ölçümleri yapılmıştır [45].

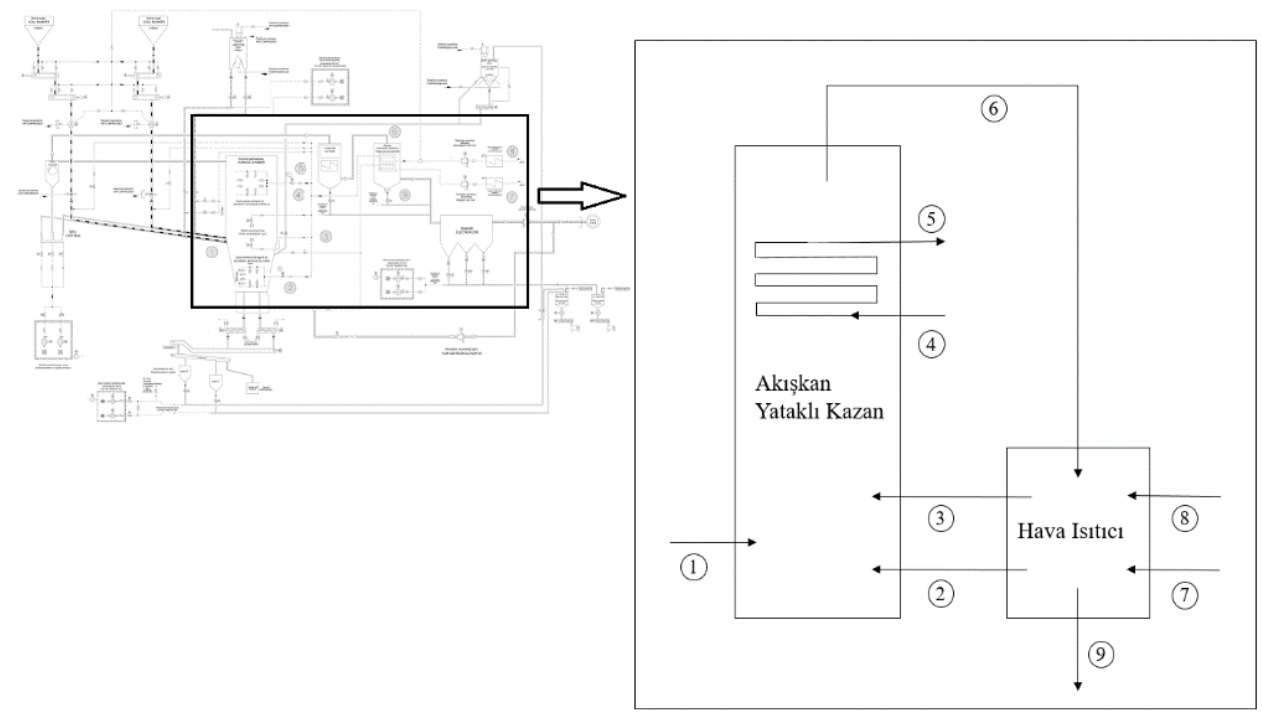

Şekil 1. Kazan ve hava ısıtıcısı basitleştirilmiş akış şeması

\section{EKSERJİ ANALİZI}

Termodinamiğin ikinci yasasına dayanan ekserji, enerjinin kullanılabilir kısmı olarak ifade edilmektedir. Bunun yanı sıra Rant [46], bir sistemin ekserjisini sistemi bir 1sı rezervuarı ile dengeye getiren ve maksimum entropiye ulaşan bir işlem sırasında mümkün olan azami yararlı iş olarak tanımlamıştır. Bejan [47] ise, çevresiyle etkileşim halinde olan bir sistemde gerçekleşen ısı transferinin, sadece çevresiyle olması halinde elde edilebilecek maksimum teorik iş olarak belirtmiştir. Çengel [48], ekserjiyi belirli bir haldeki sistemden elde edilebilecek en fazla yararlı iş olarak tanımlamıştır.

Bir sistemin ekserji değeri ölü hal koşullarında sıfırdır. Bu çalışmada sistem ölü hal koşulu $25^{\circ} \mathrm{C}\left(\mathrm{T}_{0}\right)$ ve $101,325 \mathrm{kPa}\left(\mathrm{P}_{0}\right)$ olarak kabul edilmiştir. Bunun yanı sıra hava ideal gaz olarak ve incelenen sistemin ise sürekli halde çalıştığı kabul edilmiştir. Bu çalışmada kazanın gerçek çalışma koşullarındaki performansını görmek için testlerden elde edilen sıcaklıkların ortalaması olan $17,27^{\circ} \mathrm{C}$ ve uzun yıllara dayalı sıcaklık ortalamalarına bağlı olarak $12^{\circ} \mathrm{C}, 15^{\circ} \mathrm{C}, 20^{\circ} \mathrm{C}, 28^{\circ} \mathrm{C}$ ve $30^{\circ} \mathrm{C}$ için hesaplamalar yapılmıştır. Nükleer, elekriksel, manyetik ve yüzey gerilmelerinin olmadığ termodinamik bir çevrimde fiziksel $\left(\dot{\mathrm{ex}}^{\mathrm{PH}}\right)$, kinetik $\left(\dot{\mathrm{e}} \mathrm{x}^{\mathrm{KN}}\right)$, potansiyel $\left(\dot{\mathrm{e} x}{ }^{\mathrm{PT}}\right)$ ve kimyasal ekserji (ex ${ }^{\mathrm{CH}}$ ) bileşenleri dikkate alındığında özgül ekserji (èx) Denklem 1'deki gibi ifade edilebilir,

$$
\dot{e} x=\dot{e} x^{P H}+\dot{e} x^{C H}+\dot{e} x^{K N}+\dot{e} x^{P T}
$$

Kazan performansı incelemesinde sistemin hızında ve yüksekliğinde bir değişim olmadığı için bu çalışmada kinetik ve potansiyel ekserji hesaba katılmamıştır. Sonuç olarak her bir noktanın akış ekserjisi (Ėx) Denklem 2'deki gibi ifade edilir,

$$
\dot{E} x=\dot{m}\left(\dot{e} x^{P H}+\dot{e} x^{C H}\right)
$$


$\dot{m}$ kütlesel akış debisini ifade etmektedir. Ele alınan sistemin veya düğüm noktasının özgül fiziksel ekserjisi Denklem 3'deki gibi tanımlanır. İncelenen düğüm noktalarında akışkanın ideal gaz olarak nitelendirildiği durumunda ise o noktanın fiziksel ekserji hesabında Denklem 4 kullanılır,

$$
\begin{aligned}
& \dot{e}_{x} P H=\left(h-h_{0}\right)-T_{0}\left(s-s_{0}\right) \\
& \dot{e x} P H=\bar{c} p\left[\left(T-T_{0}\right)-T_{0} \ln \frac{T}{T_{0}}\right]+R_{g} T_{0} \ln \frac{P}{P_{0}}
\end{aligned}
$$

h, s, T ve P sırasıyla entalpi, entropi, sıcaklık ve basıncı ifade etmektedir. $\bar{c}_{p}$ molar özgül 1sıyı, $\mathrm{R}_{\mathrm{g}}$ üniversal gaz sabitini ifade etmektedir. 0 indisi ise ölü hal koşulundaki değerini ifade etmektedir. Yukarıda verilen $\bar{c}_{p}$ değeri ise Denklem 5 kullanılarak hesaplanmıştır,

$$
\bar{c}_{p, b g}=\left(x_{\mathrm{O} 2} \times \bar{c}_{p, \mathrm{O} 2}\right)+\left(x_{\mathrm{CO} 2} \times \bar{c}_{p, \mathrm{CO} 2}\right)+\left(x_{\mathrm{CO}} \times \bar{c}_{p, \mathrm{CO}}\right)+\left(x_{\mathrm{SO} 2} \times \bar{c}_{p, \mathrm{SO} 2}\right)+\left(x_{\mathrm{N} 2} \times \bar{c}_{p, \mathrm{~N} 2}\right)
$$

Kimyasal ekserji hesabında çevrenin ölü hal koşulları başlangıç durumu olarak ele alınmaktadır. Bu çalışmada ideal gazlar için molar kimyasal ekserji değeri Denklem 6 kullanılarak hesaplanır,

$$
\bar{e} x_{\text {idea } \lg a z}^{C H}=\sum_{k} x_{k} e x_{k}^{C H}+R T_{0} \sum_{k} x_{k} \ln x_{k}
$$

$\mathrm{Bu}$ denklemde xk terimi gaz karışımında bulunan bileşenin mol fraksiyonu ve $e_{k}^{C H}$ ise bileşenin standart molar kimyasal ekserjisini belirtmektedir. Bu çalışmada ayrıca suyun molar ekserjisi Denklem 7 kullanılarak hesaplanır,

$$
\bar{e} x_{s u}^{C H}=R T_{0} \ln \left(P_{\text {doyma }}\left(T_{0}\right) / P_{\infty}\right)
$$

Literatürde kömürün kimyasal ekserjisini hesaplamak için bir çok ampirik formüller yer almaktadır. Bu ifadelerin kimi yanma denklemlerine kimileri ise kömürün içeriğindeki elementlerin molar fraksiyonlarına dayanmaktadır. İkinci yaklaşıma göre Szargut ve Strylska, kükürtün etkisini dikkate almayıp kömürün içerdiği su buharını hesaba kattıkları ifadeyi geliştirmişlerdir [26,49]. Bu ifadeye göre kömürün kimyasal ekserjisi Denklem 8 kullanılarak hesaplanır,

$$
\text { ex } \mathrm{x}^{\mathrm{CH}}=\Phi_{\text {kömür }}\left(H_{u_{k o ̈ m u ̈ r}}+w h_{f g}\right)
$$

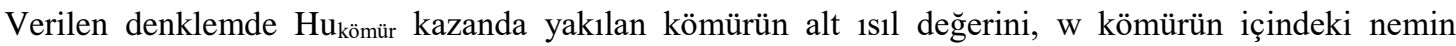
oranını, $h_{\mathrm{fg}}$ ise su buharının entalpisini ve $\Phi_{\text {kömür }}$ ise yakıt ekserjisinin alt 1 sıl değere oranını vermektedir. Bu değer Denklem 9 kullanılarak hesaplanır [26],

$$
\Phi_{\text {kömür }}=1,0437+0,1812 \frac{h}{c}+0,0610 \frac{o}{c}+0,0404 \frac{n}{c}
$$

Denklemde verilen $\mathrm{c}, \mathrm{h}$, o ve $\mathrm{n}$ ifadeleri kömürün içindeki bu elementlerin molar fraksiyonlarını ifade etmektedir. Belirlenen her bir düğüm noktasının ekserji değerleri belirlendikten sonra kazan ve hava ısıtıcısının ekserji dengeleri Tablo 2'de verildiği gibi oluşturulmuştur [45]. Enerjinin aksine ekserji korunmamaktadır. Sistemin çalışma koşullardan ölü hal koşullarına gelinen süreçte ekserji tersinmezliklerden dolayı yıkıma uğramaktadır. Yıkıma uğrayan ekserjinin miktarının ve yerinin bilinmesi incelenen sistemin gelişimi için yol gösterici olmaktadır. Bu sebeple incelenen her iki sistemdeki ekserji yıkım değerleri oluşturulan ekserji dengesinden çıkarılmıştır. Son olarak ise kazan için, Denklem 12 hava 1sıtıcı için, Denklem 15 kullanılarak ekserji verimleri hesaplanmıştır. 
Tablo 2. Kazan için ekserji dengesi, ekserji kaybı ve ekserji verimi denklemleri

\begin{tabular}{|c|c|c|c|c|c|}
\hline & Denklemler & No & & & \\
\hline Kazan & & & & $\uparrow$ & \\
\hline Ekserji Dengesi & $\dot{E}_{x_{1}}+\dot{E}_{x_{2}}+\dot{E}_{x_{3}}-\dot{E}_{x_{y}}=\left(\dot{E}_{x_{5}}-\dot{E}_{x_{4}}\right)+\dot{E}_{x_{6}}$ & (10) & & (4) Baca g & \\
\hline Ekserji Yıkımı & $\dot{E}_{x_{y}}=\left(\dot{E}_{x_{1}}+\dot{E}_{x_{2}}+\dot{E}_{x_{3}}\right)-\left[\left(\dot{E}_{x_{5}}-\dot{E}_{x_{4}}\right)+\dot{E}_{x_{6}}\right]$ & (11) & (1) $\stackrel{\text { Kömür }}{\longrightarrow}$ & & 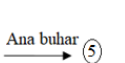 \\
\hline Ekserji Verimi & $\psi_{\text {kazan }}=\left[\left(\dot{E}_{x 5}-\dot{E}_{x 4}\right)+\dot{E}_{x 6}\right] /\left[\dot{E}_{x 1}+\dot{E}_{x 2}+\dot{E}_{x 3}\right]$ & (12) & $\begin{array}{l}\text { Birincil } \\
\text { (2) hava } \\
\text { (3) } \\
\text { İincil hava }\end{array}$ & Kazan $\rangle$ & Besleme suyu \\
\hline Hava Isıtıcı & & & & & \\
\hline Ekserji Dengesi & $\left(\dot{E}_{x_{6}}-\dot{E}_{x_{9}}\right)-\dot{E}_{x_{y .}}=\left(\dot{E}_{x_{2}}-\dot{E}_{x_{7}}\right)+\left(\dot{E}_{x_{3}}-\dot{E}_{x_{8}}\right)$ & (13) & & (7) & \\
\hline Ekserji Yıkımı & $\dot{E}_{x y .}=\left(\dot{E}_{x 6}-\dot{E}_{x 9}\right)-\left[\left(\dot{E}_{x 2}-\dot{E}_{x 7}\right)+\left(\dot{E}_{x_{3}}-\dot{E}_{x_{8}}\right)\right]$ & $(14$ & & Hava Istitic & \\
\hline Ekserji Verimi & $\psi_{h . l s i t l c l}=\left[\left(\dot{E}_{x 2}-\dot{E}_{x 9}\right)+\left(\dot{E}_{x 3}-\dot{E}_{x 10}\right)\right] /\left(\dot{E}_{x 7}-E_{x 8}\right)$ & (15) & & (8) & \\
\hline
\end{tabular}

Ekserji yıkımı ve ekserji veriminin yanı sıra incelenen sistemin performansını ortaya koymak için farklı parametreler incelenmiştir. Nispi ekserji yıkımı oranı $(\chi)$ ile bütün sistemde gerçekleşen toplam ekserji yıkımı içinde sistemi oluşturan alt bileşenlerin oranı belirlenebilir ve Denklem 16'daki gibi ifade edilir [29]. İncelenen alt sistemdeki ekserji yıkımının toplam giren ekserji değerine oranı yakıt tüketim oranını $(\delta)$ ifade etmektedir ve Denklem 17 kullanılarak hesaplanır [50]. Ayrıca incelenen alt sistemin üretkenlik eksikliği oranı $(\zeta)$, incelenen alt sistemde gerçekleşen ekserji yıkımının tüm sistemden çıkan ekserji miktarına oranıdır ve Denklem 18'deki gibi ifade edilir [51]. Son olarak, Van Gool [52] tarafından önerilen sistemin daha da geliştirilebileceği miktarı gösteren ekserjetik gelişme potansiyeli ( $I \dot{P}$ ) belirlenmiştir. Bunun için Denklem 19 kullanılmıştır [53-55].

$$
\begin{aligned}
& \chi_{k}=\frac{\dot{E}_{x_{y, k}}}{\dot{E}_{x_{y, t o p l a m}}} \\
& \delta_{k}=\frac{\dot{E}_{x_{y, k}}}{\dot{E}_{x_{g ., t o p l a m}}} \\
& \zeta_{k}=\frac{\dot{E}_{x_{y, k}}}{\dot{E}_{x_{c ., t o p l a m}}} \\
& \dot{P}_{k}=\left(1-\psi_{k}\right)\left(\dot{E}_{x_{g}}-\dot{E}_{x_{c}}\right)
\end{aligned}
$$

Denklem 19'da yer alan $\psi_{\mathrm{k}}$ ekserji verimini ifade etmektedir. Bu değer kazan için Denklem 12 hava 1sıtıcısı için Denklem 15 kullanılarak hesaplanır. y, g, ç ve k indisleri sırasıyla yıkım, giren, çıkan ve incelenen her bir alt sistemi ifade etmektedir.

\section{BULGULAR VE TARTIŞMA}

Dolaşımlı akışkan yataklı kazan ve hava 1sıtıcısının ekserji analizi için gerçek veriler elde edilmiştir. Test sırasında yakılan kömürün analiz değerleri ile santralin tasarımında belirlenen kömür tasarım değerleri Tablo 3'de karşılaştırılmıştır [45]. Test sırasında yakılan kömür, tasarım değerlerine göre farklılık göstermektedir. Tasarım değerine göre alt ve üst 1sıl değeri düşük, kükürt oranı yüksek, karbon oranı ise düşük çıkmıştır. Analizler sonucunda kömürün alt ısıl değeri $5149 \mathrm{kcal} / \mathrm{kg}$, kül, nem ve kükürt oranları sırasıyla $\% 13,65, \% 11,81$ ve \%1 olarak tespit edilmiştir. Ayrıca Tablo 4 yapılan ölçümler sonucunda elde edilen baca gazı bileşenlerinin kütle oranı (\%), molar oranı (\%), molar debi (kmol/s) ve standart molar kimyasal ekserji değerlerini göstermektedir [45]. 
Tablo 3. Kazanda yakılan kömürün tasarım ve analiz değerleri

\begin{tabular}{lccc}
\hline Parametreler & Birim & Tasarım Değeri & Analiz Değeri \\
\hline $\mathrm{C}$ & $\%$ & 63,94 & 55,2 \\
$\mathrm{H}_{2}$ & $\%$ & 3,33 & 3,94 \\
$\mathrm{O}_{2}$ & $\%$ & 3,29 & 6,36 \\
$\mathrm{~N}_{2}$ & $\%$ & 2,51 & 2,08 \\
$\mathrm{~S}_{2}$ & $\%$ & 1 & 1,04 \\
$\mathrm{Nem}$ & $\%$ & 12,39 & 11,81 \\
Alt Is1l Değer & $\mathrm{kcal} / \mathrm{kg}$ & 5655 & 5149 \\
Üst Is1l Değer & $\mathrm{kcal} / \mathrm{kg}$ & 5901 & 5408 \\
\hline
\end{tabular}

Tablo 4. Baca gazı ölçüm değerleri

\begin{tabular}{|c|c|c|c|c|c|}
\hline Parametreler & Kütle Oranı (\%) & $\begin{array}{c}\text { Moleküler Küitle } \\
(\mathrm{kg} / \mathrm{kmol})\end{array}$ & Molar Oranı (\%) & $\begin{array}{c}\text { Molar debi } \\
(\mathrm{kmol} / \mathrm{s})\end{array}$ & $\begin{array}{c}\text { Standart molar kimyasal } \\
\text { ekserji }(\mathrm{kJ} / \mathrm{kmol})[36]\end{array}$ \\
\hline $\mathrm{O}_{2}$ & 3,330 & 32 & 3,25 & 0,02 & 3970 \\
\hline $\mathrm{CO}_{2}$ & 15,482 & 44,01 & 10,15 & 0,065 & 21.140 \\
\hline $\mathrm{CO}$ & 0,015 & 28,01 & 1,7 & $1,07 \mathrm{E}-4$ & 275.430 \\
\hline $\mathrm{SO}_{2}$ & 0,001 & 64,06 & 0,05 & $3,12 \mathrm{E}-6$ & 303.500 \\
\hline $\mathrm{N}_{2}$ & 81,172 & 28,01 & 86,72 & 0,555 & 720 \\
\hline
\end{tabular}

Belirlenen düğüm noktaları için yapılan sıcaklık, basınç ve debi ölçüm değerleri ve bu değerlerin termodinamik özellikleri Tablo 5'de verilmiştir [45]. Gerçek veriler üzerinden yapılan ekserji hesaplamalarında ölü hal koşulları değiştirilmiştir. Ekserji analizlerinde uygulanan standart ölü hal koşulu $25^{\circ} \mathrm{C}$ ve ortamda yapılan ölçümlerin ortalaması $17,27^{\circ} \mathrm{C}$ sıcaklıklarının yanı sıra santralin bulunduğu bölgenin iklimsel koşullarını da göz önünde bulundurarak $30^{\circ} \mathrm{C}, 28^{\circ} \mathrm{C}, 20^{\circ} \mathrm{C}, 15^{\circ} \mathrm{C}$ ve $12^{\circ} \mathrm{C}$ içinde hesaplamalar yapılmıştır. Farklı ölü hal sıcaklıklarına göre belirlenen düğüm noktalarının ekserji değerleri bir önceki bölümde oluşturulan metodoloji kullanılarak hesaplanmıştır. Bu noktalara ait ekserji değerleri Tablo 6'da verilmiştir. Ölü hal koşullarındaki değişimler kömürün ekserji değeri üzerinde herhangi bir değişime yol açmamıştır. Kömürün ekserji değerinin sahip olduğu kimyasal bileşim ve ısıl değeri ile ilişkili olduğu tespit edilmiştir. Referans çevre sicaklık değerindeki değişimlerin baca gazı, ana buhar, besleme suyu ve yakma havası ekserji değerleri üzerinde ise değişimlere yol açmıştır. Sıcaklık değerindeki artış ana buhar ve besleme suyunun ekserji değerini artırmıştır. Ancak baca gazı, birincil yanma havası ve ikincil yanma havası akışlarının ekserji değerleri düşmüştür.

Tablo 5. Düğüm noktalarının termodinamik özellikleri

\begin{tabular}{|c|c|c|c|c|c|c|}
\hline Nokta & Akışkan Tipi & Sicaklık $\left({ }^{\circ} \mathrm{C}\right)$ & Basınç (kPa) & Debi (kg/s) & $\begin{array}{l}\text { Entalpi } \\
(\mathbf{k J} / \mathbf{k g})\end{array}$ & Entropi (kJ/kg K) \\
\hline 0 & - & 25 & 101,325 & - & 104,83 & 0,3672 \\
\hline 1 & Kömür & 11,12 & 101,325 & 2,92 & & - \\
\hline 2 & Hava & 180,41 & 101,325 & 12,1 & 455,43 & - \\
\hline 3 & Hava & 171,47 & 101,325 & 3,97 & 446,32 & - \\
\hline 4 & $\mathrm{Su}$ & 93,38 & 7232,5 & 18,74 & 391,27 & 1,2317 \\
\hline 5 & Buhar & 450,34 & 4514,5 & 20,48 & 3325,007 & 6,8781 \\
\hline 6 & Baca gazı & 229,84 & 101,325 & 19 & 215,08 & - \\
\hline 7 & Hava & 35,75 & 101,325 & 12,1 & 309,3 & - \\
\hline 8 & Hava & 30,58 & 101,325 & 3,97 & 303,95 & - \\
\hline 9 & Baca gazı & 107,52 & 101,325 & 19 & 84,17 & - \\
\hline
\end{tabular}

Tablo 6. Çevre sıcaklıklarındaki değişime göre düğüm noktalarının ekserji değerleri

\begin{tabular}{|c|c|c|c|c|c|c|c|c|}
\hline No & Birim & $12^{\circ} \mathrm{C}$ & $15^{\circ} \mathrm{C}$ & $17,27^{\circ} \mathrm{C}$ & $20^{\circ} \mathrm{C}$ & $25^{\circ} \mathrm{C}$ & $28^{\circ} \mathrm{C}$ & $30^{\circ} \mathrm{C}$ \\
\hline 1 & $\mathrm{~kW}$ & $67.815,8$ & $67.815,8$ & $67.815,8$ & $67.815,8$ & $67.815,8$ & $67.815,8$ & $67.815,8$ \\
\hline 2 & $\mathrm{~kW}$ & 524,5 & 501,8 & 485 & 465 & 429,1 & 408,1 & 394,3 \\
\hline 3 & $\mathrm{~kW}$ & 158,6 & 151,4 & 146 & 139,7 & 128,3 & 121,7 & 117,3 \\
\hline 4 & $\mathrm{~kW}$ & 1923,3 & 2326,9 & 2679,5 & 3047,2 & 3770,5 & 4228 & 4497,8 \\
\hline 5 & $\mathrm{~kW}$ & 29210,6 & $29.304,7$ & $29.427,6$ & $29.513,7$ & 29.726 & 29879 & 29942,6 \\
\hline 6 & $\mathrm{~kW}$ & 5066,2 & 5025,3 & 4994,7 & 4957,7 & 4889,9 & 4851,5 & 4825,6 \\
\hline 7 & $\mathrm{~kW}$ & 86,9 & 78,7 & 72,7 & 65,8 & 53,9 & 47,3 & 43,1 \\
\hline 8 & $\mathrm{~kW}$ & 27,1 & 24,5 & 22,7 & 20,6 & 17,1 & 15,1 & 13,9 \\
\hline 9 & $\mathrm{~kW}$ & 4210,6 & 4186,6 & 4168,9 & 4147,3 & 4107,8 & 4086,4 & 4071,8 \\
\hline
\end{tabular}


Tüm sıcaklık değerlerinde, kazanda kömürün yakılmasıyla 67.815,78 kW ekserji üretilmektedir. Hava 1sıtıcısında 1sınarak kazana giren birincil ve ikincil yanma havası $25^{\circ} \mathrm{C}$ sicaklık değerinde sirasıyla $429,1 \mathrm{~kW}$ ve 128,3 kW ekserji girdisi sağlamaktadır. Kazana giren besleme suyu ve kazandan 1sıyı alarak kızgın buhar haline gelen ana buharın aynı sicaklık değerindeki ekserji değerleri sırasıyla 3770,5 kW ve $29.726 \mathrm{Kw}$ olarak hesaplanmıştır. Kazanı terk ederek hava ısıtıcısına giren baca gazının ekserjisi ve hava 1sıtıcısında 1sısını birincil ve ikincil yanma havasına veren baca gazının ekserjisi sırasıyla 4889,9 kW ve 4107,8 kW'dır.

Kazan ve hava ısıtıcısına ait ekserji akış değerleri belirlendikten sonra ekserji performans parametreleri araştırılmıştır. Tablo 7 ve Şekil 2 kazan için farklı çevre sıcaklık değerlerindeki ekserji performans değerlerindeki değişimi göstermektedir. Görüleceği üzere çevre sıcaklığındaki artış ekserji verimini düşürmektedir. Bunun aksine ekserji yıkımı değeri, nispi ekserji yıkımı oranı, yakıt tüketim oranı, üretkenlik eksikliği oranı ve ekserjetik gelişme potansiyeli değerlerinde artışa yol açmaktadır. Standart ölü hal koşulunda $\left(25^{\circ} \mathrm{C}, 101,325 \mathrm{kPa}\right)$ ekserji verimliği \%45,11 olarak gerçekleşmiştir. Sicaklık değeri $12^{\circ} \mathrm{C}^{\prime}$ ye düştüğünde ekserji verimi \%47,23'e kadar çıkmakta iken sıcaklık $30^{\circ} C^{\prime}$ 'ye çıktı̆̆ında ise ekserji verimi \%44,3'lere kadar düşmektedir. Bunun tersine standart ölü hal koşulunda ekserji yıkımı, nispi ekserji yıkımı oranı, yakıt tüketim oranı, üretkenlik eksikliği oranı ve ekserjetik gelişme potansiyeli değerleri sırasıyla 37.527,8 kW, \%99,218, $\% 54,27, \% 119,8$ ve $20.597,8 \mathrm{~kW}$ olarak tespit edilmiştir.

Tablo 7. Kazan için farklı çevre sıcaklık değerlerindeki ekserji performans değerleri değişimi

\begin{tabular}{|c|c|c|c|c|c|c|c|}
\hline Parametreler & $12^{\circ} \mathrm{C}$ & $15^{\circ} \mathrm{C}$ & $17,27^{\circ} \mathrm{C}$ & $20^{\circ} \mathrm{C}$ & $25^{\circ} \mathrm{C}$ & $28^{\circ} \mathrm{C}$ & $30^{\circ} \mathrm{C}$ \\
\hline Ekserji Verimi (\%) & 47,23 & 46,74 & 46,38 & 45,93 & 45,11 & 44,63 & 44,3 \\
\hline Ekserji Yıkımı (kW) & $36.145,4$ & $36.465,9$ & 36.704 & $36.996,3$ & $37.527,8$ & $37.843,1$ & 38057 \\
\hline Nispi Ekserji Yıkım Oranı & 0,99214 & 0,99215 & 0,99216 & 0,99217 & 0,99218 & 0,99219 & 0,9922 \\
\hline Yakıt Tüketim Oranı & 0,521 & 0,526 & 0,53 & 0,534 & 0,54 & 0,55 & 0,551 \\
\hline Üretkenlik Eksikliği Oranı & 1,09 & 1,12 & 1,13 & 1,15 & 1,19 & 1,22 & 1,24 \\
\hline Ekserjetik Gelişme Ptansiyeli $(\mathrm{kW})$ & 19073,1 & 19421,4 & 19682,2 & 20004,6 & 20597,8 & 20953,8 & 21197 \\
\hline
\end{tabular}

Çevre sıcaklığı arttıkça hava 1sıtıcısı ekserji verimi ve nispi ekserji yıkımı değerleri düşmüştür. Diğer yandan ekserji yıkımı, yakıt tüketim oranı, üretkenlik eksikliği ve ekserjetik gelişme potansiyeli miktarında artış görülmektedir. Standart ölü hal koşulunda hava 1sıtıcısının ekserji verimi \%62,19 ve ekserji yıkım miktarı ise 295,7 kW olarak hesaplanmıştır. Buna karşı bu koşullarda nispi ekserji yıkım oranı, yakıt tüketim oranı, üretkenlik eksikliği oranı ve ekserjetik gelişme potansiyeli miktarı ise sırasılyla $\% 0,782, \% 0,428, \% 1,14$ ve 115,8 kW olarak belirlenmiştir. Diğer sıcaklık değerlerindeki hava ısıtıcısının ekserji performans değerleri Tablo 8 ve Şekil 2'de verildiği gibidir.

Tablo 8. Hava 1sıtıcısı için farklı çevre sıcaklık değerlerindeki ekserji performans değerleri değişimi

\begin{tabular}{|c|c|c|c|c|c|c|c|}
\hline Parametreler & $12{ }^{\circ} \mathrm{C}$ & $15^{\circ} \mathrm{C}$ & $17,27^{\circ} \mathrm{C}$ & $20^{\circ} \mathrm{C}$ & $25^{\circ} \mathrm{C}$ & $28^{\circ} \mathrm{C}$ & $30^{\circ} \mathrm{C}$ \\
\hline Ekserji Verimi $(\%)$ & 66,51 & 65,58 & 64,86 & 63,96 & 62,19 & 61,09 & 60,31 \\
\hline Ekserji Yıkımı (kW) & 286,5 & 288,7 & 290,2 & 292,1 & 295,7 & 297,7 & 299,2 \\
\hline Nispi Ekserji Yıkım Oranı & 0,00786 & 0,00785 & 0,00784 & 0,00783 & 0,00782 & 0,00781 & 0,0078 \\
\hline Yakıt Tüketim Oranı & 0,0041 & 0,0042 & 0,0042 & 0,0042 & 0,0043 & 0,0043 & 0,0043 \\
\hline Üretkenlik Eksikliği Oranı & 0,0103 & 0,0105 & 0,0106 & 0,108 & 0,0112 & 0,0114 & 0,0115 \\
\hline Ekserjetik Gelişme Potansiyeli (kW) & 95,9 & 99,4 & 102 & 105,3 & 111,8 & 115,8 & 118,8 \\
\hline
\end{tabular}

Şekil 2'de görüleceği üzere, hava ısıtıcısının ekserji verimi kazanın bütünündeki ekserji veriminden daha yüksektir. Bu durumda kazanda yanma reaksiyonlarının gerçekleşmesiyle ortaya çıkan tersinmezliklerin, kazanın yüzeyinden kaybolan ısının yüzey alanıyla orantılı olarak daha büyük olmasının etkili olduğu değerlendirilmektedir. Nispi ekserji yıkımı oranları incelendiğinde, incelenen tüm sistemde kazanda yıkılan ekserji miktarı çok büyük bir üstünlük sağlamıştır. Bununla paralel olarak ekserjetik gelişme potansiyeli kazanda hava 1sıtıcısına göre çok yüksek çıkmıştır. Bu durum, santralde yapılacak bakım ve verim artırma çalışmalarında önceliğin kazana verilmesi gerektiğini ortaya çıkarmıştır. Şekil 2'de görüleceği üzere ortam sıcaklığının standart referans çevre sıcaklığ $25^{\circ} \mathrm{C}$ 'den aşağıya düştükçe ekserji verimi artırdı ̆̆ı ve ekserji yıkımını aşağıya çekmektedir. 

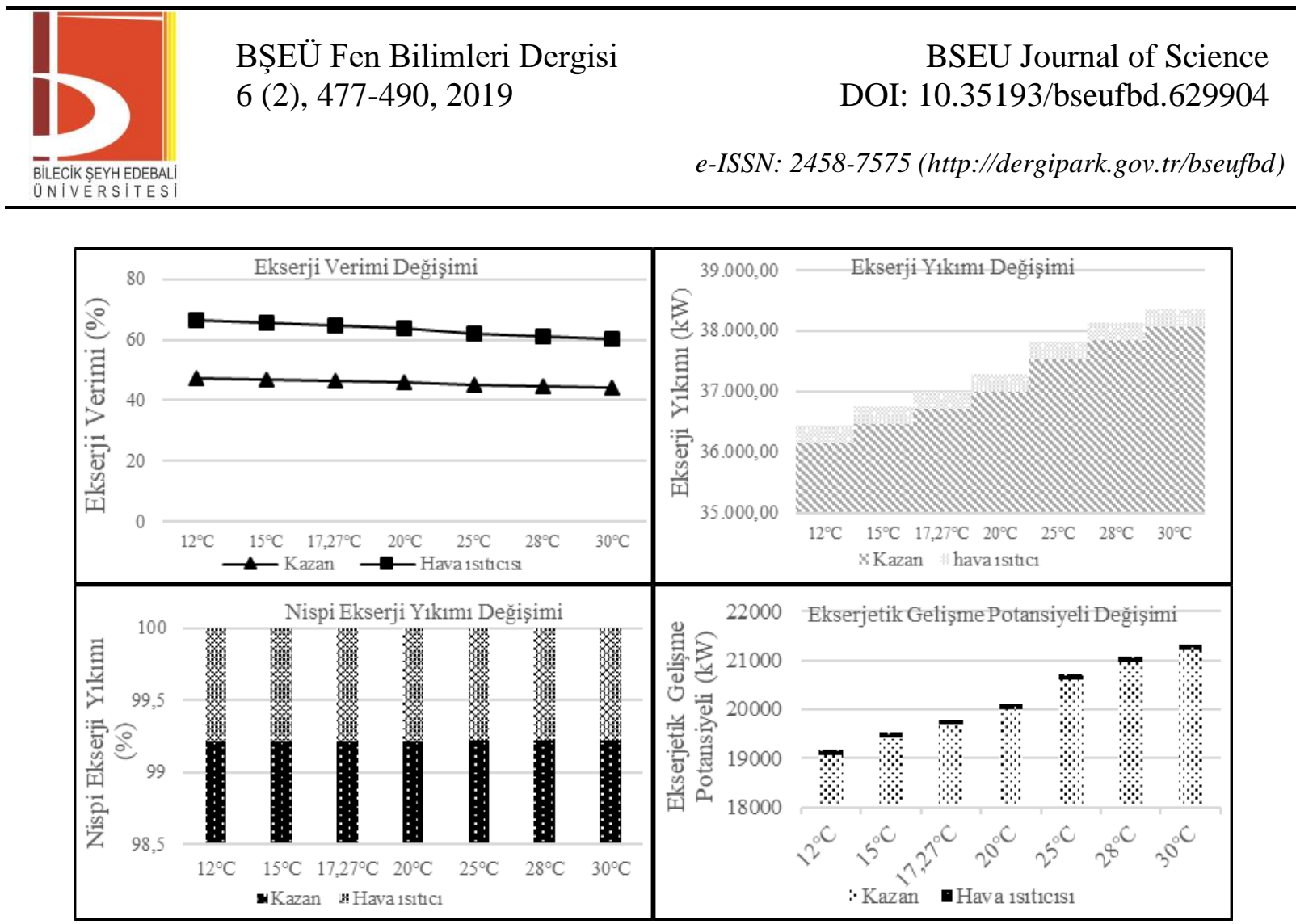

Şekil 2. Kazan ve hava ısıtıcısının farklı çevre sıcaklığına göre ekserji performans değişimleri

\section{SONUÇLAR}

Bu çalışmada, Eskişehir'in Seyitgazi ilçesinde yer alan bir endüstriyel tesisteki $75 \mathrm{t} / \mathrm{h}$ buhar kapasiteli dolaşımlı akışkan yataklı kazana konvansiyonel ekserji analizi uygulanmıştır. Kazan alt sistemlere ayrılmadan incelenmiştir. Sadece kazana verilen yanma havasını şartlandıran hava ısıtıcısı kazandan bağımsız olarak kabul edilmiştir. Kazan ve hava ısıtıcısının ekserji yıkım ve ekserji verimliliklerinin yanı sıra yakıt tüketim oranı, üretkenlik eksikliği, nispi ekserji yıkımı ve ekserjetik gelişme potansiyeli performans ölçüm parametreleri araştırılmıştır. Çalışmada ölü hal sıcaklık değerindeki değişimin $\left(30^{\circ} \mathrm{C}, 28^{\circ} \mathrm{C}, 25^{\circ} \mathrm{C}, 20^{\circ} \mathrm{C}, 17,27^{\circ} \mathrm{C}, 15^{\circ} \mathrm{C}\right.$ ve $12^{\circ} \mathrm{C}$ ) ekserji performans parametreleri üzerindeki etkisi detaylı bir şekilde tartışılmıştır. Elde edilen sonuçlar aşağıda verildiği gibi özetlenmiştir.

Yapılan hesaplamalarda, ölü hal sıcaklığı arttıkça kazan ve hava 1sıtıcının ekserji verimi düşüş göstermiştir. Buna karşı olarak ise incelenen her iki sistemde ekserji yıkım değerinde artış yaşanmıştır. Elde edilen bu sonuç literatürle uyumludur [39-44]. Standart ölü hal koşulunda kazanın ekserji verimi \%45,11 ekserji yıkım değeri ise 37,5 MW'tır. Bu sıcaklık değerinde kazanın ekserjetik gelişme potansiyeli, nispi ekserji yıkım değeri, yakıt tüketim oranı ve üretkenlik eksikliği değerleri sırasıyla 20,6 MW, \%99,2, \%54,2 ve \%119,8'dir. Ölü hal sıcaklık değeri arttıkça kazan için bu dört parametre değerlerinde artış yaşanmaktadır. Hava 1sıtıcısının ekserji verimi ve ekserji yıkım değerleri sırasıyla \%62,19 ve 295,7 kW'dır. Ölü hal sıcaklık değerinde gerçekleşen artışa bağlı olarak hava ısıtıcısının nispi ekserji yıkım oranında azalma, diğer üç parametrede ise artış gerçekleşmektedir. Hava ısıtıcısının standart ölü hal sıcaklığında nispi ekserji yıkım oranı, yakıt tüketim oranı, üretkenlik eksikliği oranı ve ekserjetik gelişme potansiyeli değerleri sırasıyla \% $0,782, \% 0,428, \% 1,12$ ve $111,8 \mathrm{~kW}$ 'dır.

Yapılan bu çalışma, kazanın genel ekserji performansını ortaya çıkarması bakımından işletmecilere yol göstermiştir. Ancak kazanda gerçekleşen tersinmezliklerin kaynaklarının ve yerlerinin tespit edilmesi faydalı olacaktır. Bu bakımdan, sistem üzerinde gelecekte yapılacak çalışmalarda kazan, alt sistemlere ayrılarak ve ileri ekserji analizi uygulanarak incelenmelidir. 


\section{KAYNAKLAR}

[1] Kanoğlu, M., Çarpınlığlu, M.Ö., Yıldırım, M. (2004) Energy and exergy analyses of an experimental open-cycle desiccant cooling system. Applied Thermal Engineering, 24, 919-932.

[2] Rosen, M.A., Le, M.N., Dincer, I. (2005) Efficiency analysis of a cogeneration and district energy system. Applied Thermal Engineering, 25, 147-159.

[3] Ozdemir, K., Hepbasli, A., Eskin, N. (2010) Exergoeconomic analysis of a fluidized-bed coal combustor (FBCC) steam power plant. Applied Thermal Engineering, 30, 1621-631.

[4] Oktay, Z. (2009) Investigation of coal-fired power plants in Turkey and a case study: Can plant. Applied Thermal Engineering, 29, 550-557. doi:10.1016/j.applthermaleng.2008.03.025

[5] Adibhatla, S., and Kaushik, S.C. (2014) Energy and exergy analysis of a super critical thermal power plant at various load conditions under constant and pure sliding pressure operation. Applied Thermal Engineering, 73, 51-65. http://dx.doi.org/10.1016/j.applthermaleng.2014.07.030

[6] Ganjehkaviri, A., Jaafar, M.N.M., Ahmadi, P., Barzegaravval, H. (2014) Modelling and optimization of combined cycle power plant based on exergoeconomic and environmental analyses. Applied Thermal Engineering, 67, 566-578. http://dx.doi.org/10.1016/j.applthermaleng.2014.03.018

[7] Zhang, C., Chen, S., Zheng, C., Lou, X. (2007). Thermoeconomic diagnosis of a coal fired power plant. Energy Conversion and Management, 48, 405-419. http://dx.doi:10.1016/j.enconman.2006.07.001

[8] Ganapathy, T., Alagumurthi, Gakkhar, R.P., Murugesan, K. (2009). Exergy analysis of operating lignite fired thermal power plant. Journal of Engineering Science and Technology Review, 2 (1), 123-130

[9] Gürtürk, M., and Oztop, H.F. (2016). Exergy analysis of a circulating fluidized bed boiler cogeneration power plant. Energy Conversion and Management, 120, 346-357. http://dx.doi.org/10.1016/j.enconman.2016.05.006

[10] Erdem, H.H., Akkaya, A.V., Cetin, B..., and Atas, S. (2009) Comparative energetic and exergetic performance analyses for coal-fired thermal power plants in Turkey. International Journal of Thermal Sciences, 48, 2179-2186. doi:10.1016/j.ijthermalsci.2009.03.007

[11] Koroneos, C.J., Fokaides, P.A., Christoforou, E.A. (2014) Exergy analysis of a 300 MW lignite thermoelectric power plant. Energy:75, 304-311. http://dx.doi.org/10.1016/j.energy.2014.07.079

[12] Pattanayak, L., and Sahu, J.N. (2015) Steady state modeling on energy and exergy analysis of a pulverized coal fired thermal power plant. Asia-Pacific Journal Chemical Engineering, 10, 876-884.

[13] Bolatturk, A., Coskun, A., Geredelioglu, C. (2015) Thermodynamic and exergoeconomic analysis of Çayırhan thermal power plant. Energy Conversion and Management, 101, 371-378. http://dx.doi.org/10.1016/j.enconman.2015.05.072

[14] Ahmadi, G.R., and Toghraie, D. (2016) Energy and exergy analysis of Montazeri Steam Power Plant in Iran. Renewable and Sustainable Energy Reviews, 56:454-463. http://dx.doi.org/10.1016/j.rser.2015.11.074

[15] Si, N., Zhao, Z., Su., S..., and Xiang, J. (2017) Exergy analysis of a 1000 MW double reheat ultrasupercritical power plant. Energy Conversion and Management, 147, 155-165. http://dx.doi.org/10.1016/j.enconman.2017.05.045

[16] Vandani, A.M.K., Bidi, M., Ahmadi, F. (2015) Exergy analysis and evolutionary optimization of boiler blowdown heat recovery in steam power plants. Energy Converison and Management, 106, 1-9 http://dx.doi.org/10.1016/j.enconman.2015.09.018 
[17] Kang, S., Li, H., Liu, L., Lei, J., Zhang, G. (2016) Exergy analysis of a novel CHP-GSHP coupling system. Applied Thermal Engineering, 93, 308-314. http://dx.doi.org/10.1016/j.applthermaleng.2015.09.039

[18] Zhou, L., Xu, G., Zhao, S., Xu, C., Yang, Y. (2016) Parametric analysis and process optimization of steam cycle in double reheat ultra-supercritical power plants. Applied Thermal Engineering, 90, 652-660. http://dx.doi.org/10.1016/j.applthermaleng.2016.01.047

[19] Fu, C., Anantharaman, R., Jordal, K., Gundersen, T. (2015). Thermal efficiency of coal-fired power plants: From theoretical to practical assessments. Energy Conversion and Management, 105, 530-544. http://dx.doi.org/10.1016/j.enconman.2015.08.019

[20] Topal, H., Taner, T. Naqvi, S.A.H., Altınsoy, Y., in, E., Ozkaymak, M. (2017). Exergy analysis of a circulating fluidized bed power plant co-firing with olive pits: A case study of power plant in Turkey. Energy, 140, 40-46. http://dx.doi.org/10.1016/j.energy.2017.08.042

[21] Xiong, J., Zhao, H., Zheng, C. (2011) Exergy analysis of a 600 MWe oxy-combustion pulverized-coal-fired power plant. Energy Fuels, 25, 3854-3864.

[22] Han, X., Liu, M., Wu, K., Chen, W., Xiao, F., Yan, J. (2016) Exergy analysis of the flue gas pre-dried lignite-fired power system based on the boiler with open pulverizing system. Energy, 106, 285-300. http://dx.doi.org/10.1016/j.energy.2016.03.047

[23] Elhelw, M., Dahma, K.S., Attia, A. (2019) Utilizng exergy analysis in studying the performance of steam power plant at two different operation mode. Applied Thermal Engineering, 150, 285-293. https://dx.doi/10.1016/j.applthermaleng.2019.01.003

[24] Arslan, O., Kose, R. (2006) Thermoeconomic optimization of insulation thickness considering condensed vapor in buildings. Energy and Building, 38, 1400-1408. doi:http://dx.doi.org/10.1016/j.enbuild.2006.02.012

[25] Dincer, I., Rosen, M.A. (2007) Exergy, environment and sustainable development. Exergy. Amsterdam: Elsevier;36-59.

[26] Szargut, J., Morris, D.R., Steward, F.R. (1988) Exergy analysis of thermal chemical and metallurgical processes. New York: Hemisphere;

[27] Wall, G. (1977) Exergy-a useful concept within resource accounting. Göteborg, Sweden: Institute of Theoretical Physics. Report No:77-42.

[28] Rosen M.A., Dincer, I., Kanoglu, M. (2008) Role of exergy in increasing efficiency and sustainability and reducing environmental impact. Energy Policy, 36(1), 128-37.

[29] Turan, O. (2015) An exergy way to quantify sustainability metrics for a high bypass turbofan engine. Energy, 86, 722-736. http://dx.doi.org/10.1016/j.energy.2015.04.026

[30] Zhu, Y., Zhai, R., Peng, H., Yang, Y. (2016) Exergy destruction analysis of solar tower aided coal-fired power generation system using exergy and advanced exergetic methods. Applied Thermal Engineering, 108, 339-346. http://dx.doi.org/10.1016/j.applthermaleng.2016.07.116

[31] Naterer, G.F., Regulagadda, P., Dincer, I. (2010) Exergy analysis of a thermal power plant with measured boiler and turbine losses. Applied Thermal Engineering, 30, 970-976

[32] Oktay, Z. (2009) Investigation of coal-fired power plants in Turkey and a case study: can plant. Applied Thermal Engineering, 29, 550-557 
[33] Wang, N., Wu, W., Yang, Y., Yang, Z., Fu, P. (2014). Exergy evaluation of a 600 MWe supercritical coalfired power plant considering pollution emissions. Energy Procedia, 61, 1860-1863. http://dx.doi.org/10.1016/j.egypro.2014.12.229

[34] Hepbasl1, A. (2009). Exergetic modeling of oil shale-fired circulating fluidized bed systems. Energy Sources, Part A, 31, 325-337. http://dx.doi.org/10.1080/15567030801901182

[35] Callak, M., Balkan, F., Hepbasli, A. (2015). Avoidable and unavoidable exergy destructions of a fluidized bed coal combustor and a heat recovery steam generator. Energy Conversion and Management, 98, 54-58. http://dx.doi.org/10.1016/j.enconman.2015.03.039

[36] Behbahninia, A., Ramezani, S., Hejrandoost, M.L. (2017) A loss method for exergy auditing of steam boilers. Energy, 140, 253-260. http://dx.doi.org/10.1016/j.energy.2017.08.090

[37] Zhang, Q., Yi, H., Yu, Z.,..., Shen, B. (2018) Energy-exergy analysis and energy efficiency improvement of coal-fired industrial boilers based on thermal test data. Applied Thermal Engineering, 144, 614-627. https://doi.org/10.1016/j.applthermaleng.2018.08.069

[38] Sharma, M., and Singh, O. (2016) Exergy analysis of dual pressure HRSG for different dead states and varying steam generation states in gas/steam combined cycle power plant. Applied Thermal Engineering, 93, 614-622. http://dx.doi.org/10.1016/j.applthermaleng.2015.10.0132

[39] Kopac, M., and Hilalci, A. (2007) Effect of ambient temperature on the efficiency of the regenerative and reheat Çatalağzı power plant in Turkey. Applied Thermal Engineering, 27, 1377-1385

[40] Regulagadda, P., Dincer, I., Naterer, G.F. (2010). Exergy analysis of a thermal power plant with measured boiler and turbine losses. Applied Thermal Engineering, 30, 970-976. http://dx.doi.org/10.1016/j.applthermaleng.2010.01.008

[41] Eskin, N., Gungor, A., Özdemir, K. (2009). Thermodynamic analysis of a FBCC steam power plant. Energy Conversion and Management, 50, 2428-2438. http://dx.doi.org/10.1016/j.enconman.2009.05.035

[42] Ozdil, N.F.T., Tantekin, A., Erbay, Z. (2016). Energy and exergy analyses of a fluidized bed coal combustor steam plant in textile industry. Fuel, 183, 441-448. http://dx.doi.org/10.1016/j.fuel.2016.06.091

[43] Arslan, O. (2005) Seyitömer termik santralı birinci ve ikinci yasa çözümlemeleri. Yüksek Lisans Tezi, Kütahya Dumlupınar Üniversitesi, Fen Bilimleri Enstitüsü, Kütahya.

[44] Aljundi, I.H. (2009) Energy and exergy analysis of a steam power plant in Jordan. Applied Thermal Engineering, 29, 324-328. doi:10.1016/j.applthermaleng.2008.02.029

[45] Yazıcı, M. (2017) Dolaşımlı bir akışkan yataklı kazanın enerji ve ekserji analizi. Yüksek Lisans Tezi, Kütahya Dumlupınar Üniversitesi, Fen Bilimleri Enstitüsü, Kütahya.

[46] Rant, Z. (1956). Exergy, a new word for technical available work. Forsch. Ing. Wis, 22(1), 36-37.

[47] Bejan, A., Tsatsaronis, G., Moran, M.J. Thermal Design and Optimization; Wiley; New York, 1996.

[48] Çengel, Y.A., and Boles, M.A. (2008) Thermodynamics on Engineering Approach (6th edition). P.445. ISBN 978-0-07-125771-8

[49] Çomaklı, K., Karslı, S., Çomaklı, Ö., Yılmaz, M. (2004) Termal sistemlerin ekserjetik analizi. Termodinamik Dergisi, 94-98.

[50] Balli, O. (2017) Advanced exergy analyses of an aircraft turboprop engine (TPE). Energy, 124, 599-612. http://dx.doi.org/10.1016/j.energy.2017.02.121 
BȘEÜ Fen Bilimleri Dergisi

6 (2), 477-490, 2019
BSEU Journal of Science DOI: $10.35193 /$ bseufbd.629904

[51] Yazici, H. (2016) Energy and exergy based evaluation of the renovated Afyon geothermal district heating system. Energy and Buildings, 127, 794-804. http://dx.doi.org/10.1016/j.enbuild.2016.06.036

[52] Van Gool, W. (1992) Exergy analysis of industrial processes. Energy, 17, 791-803.

[53] Şöhret, Y., Açıkkalp, E., Hepbasli, A., Karakoc, T.H. (2015) Advanced exergy analysis of an aircraft gas turbine engine: Splitting exergy destructions into parts. Energy, 90, 1219-1228. http://dx.doi.org/10.1016/j.energy.2015.06.071

[54] Coban, K., Colpan, C.O., Karakoc, T.H. (2017) Application of thermodynamic laws on a military helicopter engine. Energy, 140, 1427-1436. http://dx.doi.org/10.1016/j.energy.2017.07.179

[55] Eboh, F.C., Ahlström, P., Richards, T. (2019) Evaluating improvements in waste-to-energy combined heat and power plant. Case Studies in Thermal Engineering, 14, 100476. https://doi.org/10.1016/j.csite.2019.100476 